\title{
OS MULTILETRAMENTOS E OS GÊNEROS DISCURSIVOS: SER LETRADO EM AMBIENTES DIGITAIS NA MODERNIDADE TARDIA ${ }^{1}$
}

\author{
Fernando Arthur Gregol (UNIOESTE) ${ }^{2}$ \\ Terezinha da Conceição Costa-Hübes (UNIOESTE) ${ }^{3}$
}

\begin{abstract}
RESUMO: A modernidade tardia (CHOULIARAKI; FAIRCLOUGH, 1999) trouxe consigo a ascensão dos meios digitais e de novas possibilidades de interação. Com isso, novos gêneros, ou gêneros "reconfigurados", sustentam os propósitos discursivos e formatam os novos enunciados que nos são disponibilizados todos os dias. Esta modernidade tardia, portanto, nos coloca novos desafios: ser letrados em diferentes linguagens multissemióticas e multimodais (LEMKE, 2010). Diante desse contexto, nosso objetivo é analisar de que forma o letramento digital se manifesta do ponto de vista da leitura, compreensão e produção de textos de alunos de nível avançado e nível iniciante em Língua Inglesa, num programa de ensino de línguas de uma universidade pública. Inseridos no campo de estudos da Linguística Aplicada (MOITA-LOPES, 2006), compreendemos a linguagem como uma manifestação social, dotada de características discursivas, portanto, impossível de ser descolada de seu contexto e de uma real necessidade de estudo. Trata-se, assim, de um trabalho qualitativo-interpretativista (BORTONI-RICARDO, 2008), que pretende demonstrar como os multiletramentos se fazem presentes em salas de aulas de línguas estrangeiras na atual conjuntura em que nos encontramos.
\end{abstract}

PALAVRAS-CHAVE: Multiletramentos. Gêneros Multimodais. Ensino de Língua Estrangeira.

ABSTRACT: Late modernity (CHOULIARAKI; FAIRCLOUGH, 1999) has brought digital rise and new possibilities of interaction. Thereby, new genres, or 'redesigned' genres, support discourse purposes e format new enounces that are delivered us every day. Thus, late modernity challenge us at certain point: be literate in different semeiotic and modal aspects (LEMKE, 2010). Therefore this context, our aim is to analyze in which way digital literacy occurs from de point of view of reading, comprehension e textual production of students from advanced and beginner level of English, in an institutional language teaching program of a public university. Involved by Applied Linguistics (MOITA-LOPES, 2006), we comprehend language as social event, full of discourse characteristics, wherefore, impossible to be dislocated from its context and a real studying need. That way, this research is a qualitative-interpretative (BORTONI-RICARDO, 2008), that pretends demonstrate how multiliteracies are present in foreign language classrooms nowadays.

KEYWORDS: Multiliteracies. Multimodal Genres. Foreign Language Teaching.

\section{INTRODUÇÃO}

A Linguística Aplicada (LA) enquanto campo epistemológico das ciências humanas traz uma vasta gama de trabalhos que buscam abordar problemas relacionados à língua, seja do ponto de vista da construção da identidade, seja da educação linguística de seus usuários. Como disciplina, atuou, principalmente, com o ensino de Língua Estrangeira (LE), porém seu foco, nos dias atuais, enquanto campo de pesquisa que dialoga com outras disciplinas das

\footnotetext{
${ }^{1}$ Agradecemos, de forma especial, ao CNPq pela bolsa de pesquisa que possibilitou a escritura do trabalho.

2 Discente do Programa de pós-graduação em Letras - Linguagem e Sociedade - nível mestrado - da Universidade Estadual do Oeste do Paraná - UNIOESTE. E-mail: fgregol70@gmail.com

${ }^{3}$ Professora doutora do Programa de pós-graduação - Linguagem e Sociedade - da Universidade Estadual do Oeste do Paraná - UNIOESTE. E-mail: tehubes@gmail.com
} 


\section{$=$ TRAMA $=$}

ciências humanas (MOITA-LOPES, 2006), é entender os problemas linguísticos, cada vez mais envolvidos com os fatores externos à língua, vista como uma prática social.

Os multiletramentos, envolvidos pelo campo de estudos da LA, fazem referência a uma realidade muito comum e, conforme Rojo (2009), como um dos problemas mais visíveis na escola da modernidade: o distanciamento entre as práticas sociais de uso da linguagem e a escola. A primazia da escola em apontar para um ensino de formas, descolado das situações reais de uso de uma língua, torna o aluno incapaz de interagir em situações sociais bastante comuns, além, é claro, de promover o analfabetismo funcional e o abandono do meio escolar.

A sociedade caminha a passos largos para o mundo das tecnologias digitais, que, obviamente, adentraram os mais diversos setores de nossa sociedade. Essa realidade apresenta uma prática de uso da linguagem que envolve múltiplas semioses e múltiplos gêneros discursivos. A inserção dessas novas tecnologias e objetos digitais em nosso meio se dá por conta daquilo que Chouliaraki e Fairclough (1999) chamam de modernidade tardia 4 . Os autores definem o perfil daqueles que estão envoltos por esta sociedade como:

Elas [as pessoas] são organizadas ao longo de grandes distâncias de tempo e espaço - globalizadas - e dependem de meios tecnológicos sofisticados como forma de mediação. Práticas face a face muito comuns estão crescentemente dependentes (poderíamos dizer, colonizados por) dessas complexas práticas modernas, bem como se apropriando delas. [...] Resumindo, a modernidade envolveu uma mudança radical nas práticas sociais e na relação entre essas práticas sociais (CHOULIARAKI; FAIRCLOUGH, 1999, p. 42 - tradução nossa) $)^{5}$.

Tendo isso em vista, nosso objetivo, neste artigo, é observar como os recursos de natureza multissemiótica e multimodal são utilizados por adolescentes, aprendizes de língua inglesa (TEEN I e Avançado Teen), de um programa institucional de ensino de Línguas. A partir de uma produção textual solicitada pela docente da turma, foi possível analisar como uma prática de letramento escolar, baseada na vida cotidiana, focada em um gênero do discurso, envolveu uso de recursos multimodais que influenciaram diretamente o conteúdo temático, o estilo e a construção composicional dos enunciados.

Trata-se, portanto, de um trabalho qualitativo-interpretativista (BORTONI-RICARDO, 2008), pois analisamos e interpretamos enunciados concretos, considerando o método sociológico do Círculo de Bakhtin ${ }^{6}$, em que se parte da análise de fatores sociais para entender sua ligação com o conteúdo verbo-visual dos enunciados.

$\mathrm{Na}$ próxima seção, apresentamos, brevemente, alguns aspectos da teoria dos multiletramentos, consoante com a teoria dos gêneros do discurso de Bakhtin (2011[1979]). A discussão teórica, portanto, pauta-se em autores como os pesquisadores do New London

\footnotetext{
${ }^{4}$ O termo "modernidade tardia" é empregado por Chouliaraki e Fairclough (1999) para se referir ao atual período histórico que vivemos. Entretanto, diversos teóricos da filosofia, da sociologia, dos estudos culturais, da Análise Crítica do Discurso e, até mesmo, da Linguística Aplicada, empregam termos diversos para o mesmo fenômeno, tais como, modernidade líquida (BAUMAN, 1999), pós-fordismo (SANTAELLA, 2003), globalização (BARTON; LEE, 2015), hipermodernidade (ROJO; BARBOSA, 2015), etc.

${ }^{5}$ They [people] are often organised across great distances of time and space - globalised - and depend upon sophisticated technologies of mediation. Ordinary face-to-face practices are increasingly dependent upon (we might say, colonised by) these complex modern practices, as well as appropriating them. [...] In short, modernity has involved a radical change in the nature of social practices and in the relations between social practices (CHOULIARAKI; FAIRCLOUGH, 1999, p. 42).

${ }^{6}$ Círculo de Bakhtin é uma expressão cunhada por teóricos contemporâneos para caracterizar os trabalhos de um grupo de pesquisadores, dentre os quais se destacam, principalmente, Mikhail Bakhtin, Valentim Volochínov e Pavel Medevedév.
} 
Group (1996), Rojo (2009; 2012), Lemke (2010), Bakhtin (2011[1979]), Barton e Lee (2015), Rojo e Barbosa (2015) e Volóchinov (2017[1929]).

Em seguida, buscamos explanar como estes aspectos dos gêneros e das multisemioses, por meio de enunciados produzidos por alunos de língua inglesa em nível iniciante e avançado, de faixa etária adolescente. Por último, apresentamos também algumas considerações finais acerca daquilo que fora exposto em nossa análise, em relação aos aspectos teóricos apresentados.

\section{OS MULTILETRAMENTOS E OS GÊNEROS DISCURSIVOS}

O que significa ser letrado? O que é um letramento? O que é um multiletramento? Aparentemente, são perguntas fáceis de serem respondidas, uma vez que o conceito ou área de estudos se tornou tão relevante no ideário de autores que se preocupam com a educação linguística das novas gerações e que, cada vez mais, se envolvem pelos diversos ambientes multimodais. Os sujeitos são considerados multiletrados, uma vez que estão o tempo todo envolvidos, e, até mesmo, são bombardeados, pela múltipla semiotização e pela informação.

Entretanto, o New London Group (1996) ${ }^{7}$, ao empregar pela primeira vez o termo pedagogia dos multiletramentos ${ }^{8}$, defende que o conceito não trata apenas da multimodalidade e das múltiplas faces semióticas dos enunciados. O conceito abarca a múltipla inserção dos indivíduos que estão à margem da sociedade. Com essa abrangência, os teóricos não se preocupam apenas em entender o real funcionamento dos enunciados multimodais, mas também em tornar acessíveis tais recursos, como som, imagens, cores, etc., para que todos estejam aptos a usufruir deles.

Para Rojo e Barbosa (2017), toda prática multiletrada, na hipermodernidade, está centrada em gêneros. Ao definir os "gêneros do discurso" como "tipos relativamente estáveis de enunciados", Bakhtin (2011[1979]) também defende a ideia de que os gêneros se realizam, principalmente, no registro oral e no registro escrito. Lemke (2010), por sua vez acrescenta que

[...] todo letramento é letramento multimidiático: você nunca pode construir significado com a língua de forma isolada. É preciso que haja sempre uma realização visual ou vocal de signos linguísticos que também carrega significado não-linguístico (por ex.: tom da voz ou estilo da ortografia). Para funcionarem como signos, os signos devem ter alguma realidade material, mas toda forma material carrega, potencialmente, significados definidos por mais de um código. Toda semiótica é semiótica multimídia e todo letramento é letramento multimidiático (LEMKE, 2010, p. 456).

O pensamento do autor dialoga diretamente com a concepção dialógica da linguagem, pois o Círculo de Bakhtin foi responsável por defender uma filosofia de linguagem que primava pela análise da linguagem em sua relação com o ambiente histórico-social que a circunda. Em outras palavras, para os autores, partir de um contexto histórico-espacial, axiológico e temático é tarefa imprescindível a qualquer analista da linguagem. Essa compreensão fica clara em Volóchinov (2017[1929]), que, ao propor o método sociológico, defende que o analista da linguagem deve analisar:

[...] 1) formas e tipos de interação discursiva em sua relação com as condições concretas; 2) formas dos enunciados ou discursos verbais singulares em relação

\footnotetext{
7 "Grupo de Nova Londres", em Língua Portuguesa.

${ }^{8}$ Pedagogia dos Multiletramentos (em inglês, Pedagogy of multiliteracies) é um termo empregado pelos pesquisadores do Grupo de Nova Londres, dentre os quais estão Courtney Cazden, Bill Cope, Norman Fairclough, James Gee, Mary Kalantzis, Gunther Kress, Allan Luke, Carmen Luke, Sarah Michaels e Martin Nakata.
} 
estreita com a interação da qual são parte, isto é, os gêneros dos discursos verbais determinados pela interação discursiva na vida e na criação ideológica; 3) partindo disso, revisão das formas da língua em sua concepção linguística habitual (VOLÓCHINOV, 2017[1929], p. 220, o grifo é nosso).

Ao considerar tal orientação, é correto afirmar que a análise dos gêneros do discurso em Bakhtin, parte de um contexto extraverbal (isto é, histórico, espacial, social, axiológico, temático), para que, em seguida, possamos entender as formas da língua que se concretizam em enunciados, sem perder de vista a análise dos conteúdos de natureza sociológica. É fundamental, portanto, a análise dos gêneros sustentada pelo método sociológico, situando-os na perspectiva dos multiletramentos, pois, para Lemke (2010), "um letramento é sempre um letramento em algum gênero e deve ser definido com respeito aos sistemas sígnicos empregados, às tecnologias materiais usadas e aos contextos sociais de produção, circulação e uso de um gênero particular" (LEMKE, 2010, p. 457).

Logo, há uma relação intrínseca entre os multiletramentos e os gêneros do discurso, uma vez que toda prática de letramento é permeada por um gênero específico que atende aos propósitos dialógicos do usuário de uma determinada língua. Por isso, somos letrados em certas práticas e não em outras, pois vivemos algumas e outras não. Cada agência de letramento (escola, jornal, igreja, literatura) tem práticas de letramento específicas e, por consequência, tais práticas dão origem a novos gêneros discursivos (Cf. BARTON; LEE, 2015). As agências de letramento, por sua vez, remetem diretamente aos "campos de atividade humana" (BAKHTIN, 2011[1979]), já que, de acordo com o próprio Bakhtin, os campos organizam as formas de interação e convencionam quais gêneros formatarão os enunciados que se originam em determinado campo.

Por fim, ao tomarmos os gêneros como protagonistas nas diversas práticas de letramento que nos circundam, propõem-se o ponto de vista de Bakhtin (2011[1979]), que concebe o gênero numa configuração tripartite: conteúdo temático, estilo linguístico e construção composicional. Tais categorias não devem, porém, ser enxergadas separadas, pois juntamente ao conteúdo extraverbal, formam a essência do enunciado e, por consequência, do gênero em si.

O conteúdo temático, no ideário do Círculo, trata do(s) objeto(s) discursivo(s) que circundam um determinado enunciado. Todo enunciado tem conteúdos temáticos específicos que fazem referências diretas aos interdiscursos e a como estes são abordados em outros enunciados já vistos pelo autor de um novo enunciado. Desta forma, a seleção de recursos multimodais também faz referência à imagem discursiva que este enunciador constrói ao longo de sua caminhada, enquanto usuário de uma língua (Cf. ROJO; BARBOSA, 2015).

O estilo linguístico, de acordo com Bakhtin (2011[1979]), está relacionado à seleção de recursos fraseológicos, linguísticos e gramaticais de que se vale o autor de um enunciado. Todo gênero é dotado de estilo próprio, bem como de estilos individuais dos próprios autores de novos textos. O estilo multimodal, portanto, se configura em seleção de cores, de imagens representativas, de sons que, em ligação estreita com o conteúdo temático, fazem referências diretas aos interdiscursos.

Por último, a construção composicional de um dado enunciado trata da forma como o gênero se realiza. De acordo com Costa-Hübes (2017), a construção composicional diz respeito à forma, mas que não necessariamente é fixa e imutável. Como já foi mencionado, os gêneros são convenções de determinados campos da atividade humana, portanto, sua construção composicional é moldável em diferentes situações de enunciação. Ainda de acordo com a autora, não é este item que determina um gênero, mas sim os seus usos sociais e seu uso 


\section{$=$ TRAMA $=$}

habitual em situações enunciativas concretas. Os gêneros multimodais, de certo modo, têm formas composicionais distintas, tomando em seu escopo o som, a imagem, o movimento, etc.

Passamos, na próxima seção, a discutir e exemplificar como alunos de Língua Inglesa de um projeto institucional de extensão concebem as características do gênero multimodal "convite de festa". O corpus mostra como alunos de nível iniciante (TEEN I) e nível avançado (AVANÇADO TEEN) produziram enunciados multimodais, utilizando recursos online e estratégias multissemióticas na construção de tais enunciados.

\section{ANÁLISE DE CORPUS}

O corpus analisado neste trabalho originou-se a partir de textos produzidos por alunos do Programa de Ensino de Línguas (PEL), projeto de extensão vinculado à Universidade Estadual do Oeste do Paraná. O Programa conta com a participação de cerca de 2000 alunos, de acordo com dados obtidos na secretaria do Programa. São oferecidas aulas de oito línguas estrangeiras: alemão, espanhol, francês, grego, inglês, italiano, japonês e português, em diferentes níveis de ensino: fundamental, básico, pré-intermediário, intermediário, pósintermediário e avançado, divididos em quatro faixas etárias: crianças, adolescentes, adultos e terceira idade (sênior).

Para este trabalho, optamos por trabalhar com a turma de "Língua Inglesa - nível avançado - Teen", isto é, sexto ano de língua inglesa de alunos com faixa etária que varia dos 15 aos 17 anos. Também, a atividade foi proposta a uma turma de "Teen I" (primeiro ano de Língua Inglesa com faixa etária de 11 a 13 anos. A docente da turma é graduada em Letras Língua Portuguesa/Língua Inglesa e respectivas literaturas, especialista em Ensino da Língua Inglesa e, atualmente, concluinte do Mestrado em Letras, com ênfase em Literatura comparada, visando aos processos de tradução de obras brasileiras para a Língua Inglesa. Esta mesma docente atingiu o nível C2 ${ }^{9}$, tendo em vista o Quadro Comum Europeu de Referência, pelo Certificate of Proficiency in English (CPE), realizado pela Universidade de Cambridge.

O material usado pela turma de nível avançado é o Identities 1, da editora Richmond. Os alunos, portanto, de acordo com a classificação que se obtém no material, estão estudando conteúdos dos níveis B2 e C1. De acordo com o Quadro Comum Europeu, alunos deste nível devem ser capazes de

[...] entender uma grande quantidade de informações dificultosas, e reconhecer significados implícitos. Expressar a si mesmos de forma fluente e espontânea, sem muita busca por palavras/expressões. Usar uma linguagem flexível e efetiva para propósitos de caráter social, acadêmico e profissional. Produzir textos claros, bem-estruturados e detalhados acerca de temas complexos, mostrando controle e uso de padrões de organização, conectores e elementos coesivos (QUADRO COMUM EUROPEU DE REFERÊNCIA, s/d, p. 24, a tradução é de nossa responsabilidade $)^{10}$.

Os alunos de "Teen I" usam o material Smart Choice - Starter, da Oxford University Press. De acordo com as informações obtidas no material, eles estão no nível iniciante, ou seja,

\footnotetext{
${ }^{9}$ O nível C2 é considerado o nível mais alto do Quadro Comum Europeu, que, nos dias atuais, é uma referência para quase todos os exames de proficiência no mundo todo. Os níveis são A1 e A2 (nível básico e préintermediário), B1 e B2 (nível intermediário e pós-intermediário) e C1 e C2 (nível avançado e proficiente).

10 [...] understand a wide range of demanding, longer texts, and recognise implicit meaning. Can express him/herself fluently and spontaneously without much obvious searching for expressions. Can use language flexibly and effectively for social, academic and professional purposes. Can produce clear, well-structured, detailed text on complex subjects, showing controlled use of organisational patterns, connectors and cohesive devices (COMMON EUROPEAN FRAMEWORK OF REFERENCE, n/d, p.24).
} 


\section{$=$ TRAMA $=$}

estão no nível A1 do Quadro Comum Europeu de referência. Portanto, conforme informações obtidas no Framework, os alunos devem:

[...] entender e usar expressões familiares e diárias, além de frases, cujo objetivo é satisfazer suas necessidades concretas. Podem apresentar a si mesmos e aos outros a perguntar e responder perguntas sobre detalhes pessoais, como onde vivem, se as pessoas sabem ou não acerca daquilo que têm. Podem interagir de forma simples, provendo a outras pessoas conversas rápidas e claras para que estejam aptos a colaborar mutuamente (QUADRO COMUM EUROPEU DE REFERÊNCIA, s/d, p. 24, a tradução é de nossa responsabilidade) $)^{11}$.

Ambas as turmas têm aulas ministradas pela mesma docente. Treze alunos aceitaram participar da atividade de produção de um texto multimodal; destes, 2 estão matriculados na turma "Avançado Teen" e os outros 11 são da turma de "Teen I". Para que os alunos pudessem realizar a atividade, a docente, com a nossa participação, elaborou o seguinte exercício:

Quadro 1: Comando de produção de atividade multimodal ${ }^{12}$

Atividade Multimodal
Os feriados de final de ano estão se aproximando. Com eles, muitas pessoas
planejam festas ou unem-se a amigos, familiares, colegas de trabalho, etc. Tendo
isso em vista, crie um convite para uma das festas que será dada em sua casa. As
informações que seguem não podem faltar:
- Data
- Hora
É também importante que você escreva uma bela e convidativa mensagem, fazendo
com que seu convite seja bem-apresentado e convidativo. Selecione imagens, ou até
mesmo gifs, que combinem com o feriado e o torne um convite atrativo.

Fonte: Elaborado pelos autores e pela professora participante da pesquisa; tradução nossa.

Para exemplificar o resultado dessa atividade, escolhemos um trabalho de cada uma das turmas e analisamos no escopo deste artigo. Os alunos utilizaram recursos online, principalmente o Canva ${ }^{13}$ para produzir seus próprios convites. Ao referir-se aos feriados de

\footnotetext{
${ }^{11}[\ldots]$ understand and use familiar everyday expressions and very basic phrases aimed at the satisfaction of needs of a concrete type. Can introduce him/herself and others and can ask and answer questions about personal details such as where he/she lives, people he/she knows and things he/she has. Can interact in a simple way provided the other person talks slowly and clearly and is prepared to help (COMMON EUROPEAN FRAMEWORK OF REFERENCE, n/d, p. 24).

${ }^{12}$ Multimodal Activity Holiday season is getting closer. Along with them, many people plan a party or a gathering with friends, relatives, coworkers, etc. Bearing that in mind, create an invitation for any of those parties to be held at your house. The following information can not go missing:

-Date;

-Time;

-Address;

It is also highly important that you write a beautiful and cheerful message, making sure that your invitation is wellpresented and appealing. Select images, or even gifs, that match your holiday party and turn it into a more attractive invitation.

${ }^{13}$ O Canva é um site em que templates, imagens, ícones, gifs, editores de textos, formas e esquemas de cores são disponibilizados para que os usuários possam produzir enunciados dos mais variados gêneros multimodais. A docente das turmas já havia ensinado aos alunos a usar o recurso.
} 


\section{$=$ TRAMA $=$}

final de ano, delimitou-se o conteúdo temático para o dia de ação de graças (thanksgiving), natal (Christmas) e ano novo (New Year). Vejamos o primeiro exemplo:

Figura 1: Texto produzido pelo aluno Marcos Vieira (Avançado TEEN) ${ }^{14}$

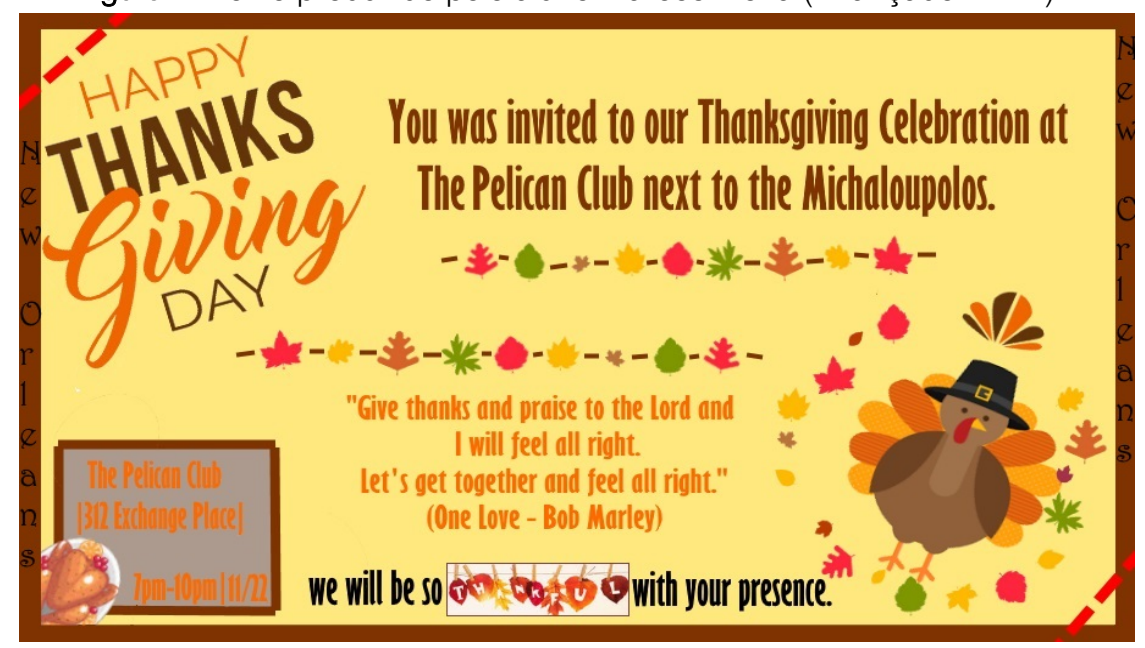

Fonte: elaborado por aluno de nível Avançado TEEN

Ao analisarmos este texto, fica evidente a escolha do aluno pelo dia de ação de graças (thanksgiving). O conteúdo temático, portanto, centra-se nos aspectos do feriado. A inserção da imagem do Peru é bastante representativa e elucidativa em relação à data comemorativa, tendo em vista que o peru assado é um prato típico dessa comemoração. Além disso, a seleção das cores amarelo e laranja (da fonte do texto), também representam o feriado, juntamente com signos semióticos típicos dos feriados de final de ano, como as folhagens, próprias dos Estados Unidos e do Canadá, que simbolizam a passagem do outono para o inverno.

Ao tratarmos dos aspectos estilísticos neste enunciado, percebemos o uso de Língua Inglesa, uma vez que a atividade fez parte do estudo desta língua. Problemas de ordem gramatical surgem, mas não prejudicam a compreensão do enunciado, como, por exemplo em "You was [were] invited to our Thanksgiving Celebration at the Pelican Club next to the Michaloupolos" (Você foi convidado para o nosso Dia de Ação de Graças no Clube Pelicano, próximo ao Michaloupolos). O uso da voz passiva faz com que o aluno traga um dos aspectos mais importantes do convite: ser convidativo e não imperativo. Tal estratégia contribui para que atinja seu propósito discursivo.

Ao fazer uma relação interdiscursiva, traz um trecho da música de Bob Marley para o enunciado, que diz: "Give thanks and praise to the Lord and I will fell all right. Let's get together and fell all right" (Agradeça e louve a deus para que eu me sinta bem. Vamos nos unir e nos sentirmos bem). O fragmento da canção é representativo no sentido de que, neste feriado, é comum agradecer por coisas boas adquiridas ao longo do ano e reunir familiares e amigos. Por último, na mensagem "We will be so thankful with your presence (Ficaremos muito agraciados com sua presença)", o tom apelativo da palavra "thankful" faz com que o tom argumentativo ajude o enunciador a fortalecer o seu propósito discursivo. A organização das imagens e do esquema de cores escolhidos também funcionam como aspectos de natureza estilística.

Ao tratarmos da construção composicional, percebemos que o aluno contempla todos os itens solicitados pela docente no comando de produção, mas, fica livre para trazer outros aspectos que julgou relevante. Portanto, local, data e hora são mencionados, mensagens de

\footnotetext{
${ }^{14}$ Os nomes de alunos utilizados, neste trabalho, são fictícios. Respeitou-se apenas as iniciais do verdadeiro nome do aluno.
} 


\section{$=$ TRAMA $=$}

thanksgiving são feitas com a devida referência e imagens e objetos semióticos são trazidos na constituição estilístico-composicional do enunciado.

De um modo geral, entendemos que os aspectos temáticos, estilísticos e composicionais unem-se às diversas linguagens multissemióticas, que estabelecem um propósito discursivo bem-definido. A seleção da temática é que faz com que o enunciador escolha os recursos de linguagem, que estabelecem, por consequência, uma relação interdiscursiva com este tema. A construção composicional, assim sendo, também é afetada, uma vez que aspectos estilísticos e semióticos passam a ser itens praticamente obrigatórios na construção do enunciado.

Vejamos agora como se deu a produção de uma aluna de nível iniciante, ou seja, "Teen I". A aluna, por sua vez, optou pelo feriado de Ano Novo (New Year), especificamente o último dia, isto é, o dia da virada do ano. O texto está representado na imagem a seguir:

Figura 2: Texto produzido pela aluna Bárbara Azevedo (TEEN I)

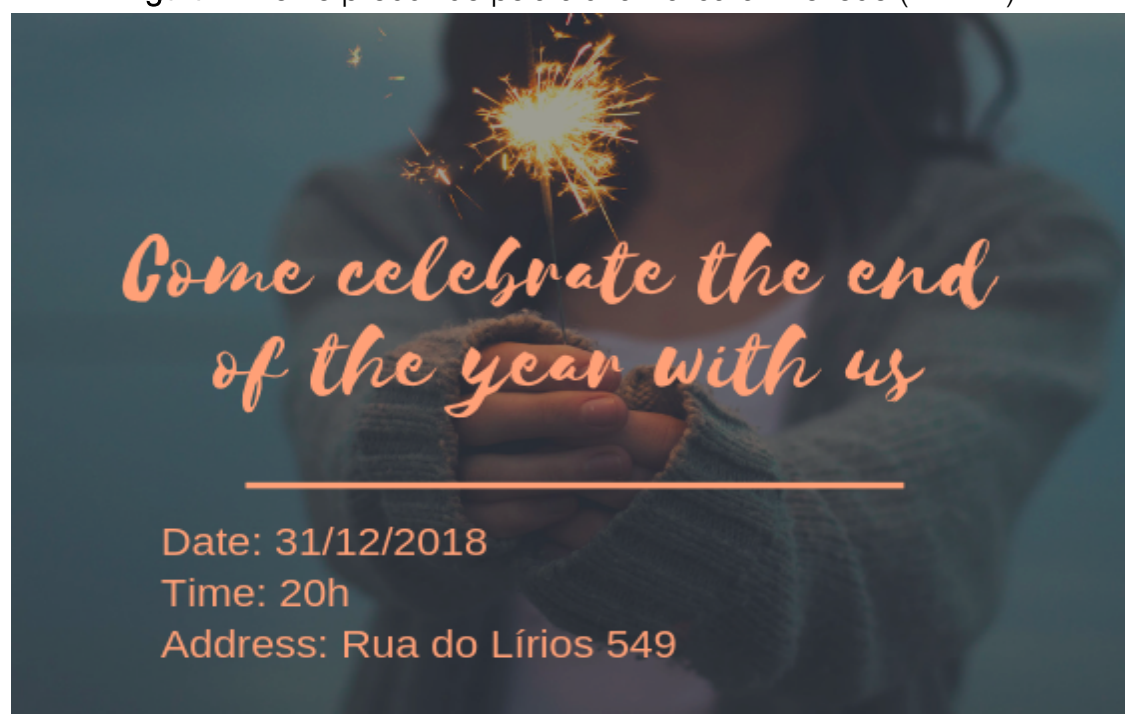

Fonte: elaborado por aluna de nível TEEN I

Neste último trabalho, tanto os aspectos multimodais, quanto o uso de Língua Inglesa é bem mais simples. Do ponto de vista do conteúdo temático, a imagem representa a festividade do ano novo. A vela pode simbolizar o nascer de um novo ano. Há o tom da felicidade da pessoa que a segura, usado como um modalizador para tornar o texto mais atraente.

Em se tratando do estilo de linguagem, utilizado pela autora do enunciado, percebe-se o uso mais escasso da Língua Inglesa, em virtude de seu nível de aprendizado. A mensagem "Come celebrate the end of the year" (Venha comemorar o fim do ano), é dotada de imperativo convidativo, que funcionam positivamente com os demais aspectos. A cor da fonte é clara e fortalece, portanto, a mensagem que se quer passar.

Por último, quanto à composição do enunciado, percebe-se que a enunciadora ainda domina poucos aspectos e optou apenas em seguir o comando de produção da docente responsável pela atividade. Desse modo, tem-se a data, o local, a hora e uma pequena mensagem convidativa. Os aspectos de natureza multimodal estão presentes e também incorporam o enunciado.

Entendemos que, ainda que de uma forma mais simples, os aspectos de natureza verbo-visual se fazem presentes no enunciado, uma vez que os aspectos multimodais, tais como cores, seleção de fonte, posicionamento e efeitos de edição de texto ajudam a estabelecer uma mensagem que será passada por meio deste enunciado. 


\section{$=$ TRAMA $=$}

\section{CONCLUSÃO}

Uma prática de letramento bem-situada e uma situação real de uso de linguagem aproximaram os aprendizes dos multiletramentos, pois conseguiram demonstrar bom domínio do gênero solicitado pela docente, bem como de recursos multimodais e/ou multissemióticos na hora de produzir seu enunciado. Todas as três características dos gêneros, na perspectiva de Bakhtin (2011[1979]), se fizeram presentes em ambos enunciados, além de estarem presentes no comando de produção, que fora solicitado pela professora das turmas. E, a partir dos dados analisados, percebe-se que os alunos são capazes de interagir, de acordo com a classificação do Quadro Comum Europeu de Referência.

E quanto à multimodalidade? Foi possível verificar, por meio desta análise que, assim como não conseguimos separar os aspectos de natureza social dos aspectos verbais dos enunciados, também não se pode separar a multimodalidade e os recursos semióticos das categorias colocadas por Bakhtin para o estudo dos gêneros. Isto significa dizer que a imagem, a cor, etc. representam a forma como os autores constroem o enunciado e fazem relação direta com a forma como estes autores do enunciado concebem o tema. Também são usadas como um recurso de estilo, pois são altamente argumentativas, além de harmonizarem com os demais aspectos da textualidade.

Ainda, por último, são itens indispensáveis na era digital e, portanto, passam a fazer parte da construção composicional de qualquer enunciado que seja formatado nos parâmetros de um gênero multimodal.

\section{REFERÊNCIAS}

BAKHTIN, Mikhail. [1979]. Estética da Criação Verbal. Tradução do russo por Paulo Bezerra. 6. ed. São Paulo: Martins Fontes, 2011.

BARTON, David; LEE, Carmen. Linguagem online: textos e práticas digitais. Tradução do inglês por Milton Camargo Mota. São Paulo: Parábola Editorial, 2015.

BAUMAN, Zygmunt. Globalização: as consequências humanas. Rio de Janeiro: Jorge Zahar Editores, 1999. BORTONI-RICARDO. O professor pesquisador: introdução à pesquisa qualitativa. São Paulo: Parábola Editorial, 2008.

COMMON EUROPEAN FRAMEWORK OF REFERENCE FOR LANGUAGES: Learning, teaching, assessment. Disponivel em: < https://goo.gl/rNSmTa>; Acesso em 20 nov. 2018.

CHOULIARAKI, Lillie; FAIRCLOUGH, Norman (2001). Discourse in late modernity: Rethink Critical Discourse Analysis. Edinburg: Edinburg University Press.

COSTA-HÜBES, Terezinha da Conceição. A pesquisa em ciências humanas sob um viés bakhtiniano. Revista Pesquisa Qualitativa. São Paulo, v.5, n.9, p. 552-568, dez. 2017.

GEE, James Paul. Situated Language and Learning: A critique of traditional Schooling. New York: Routledge, 2004.

KRESS, Gunther. Multimodality: A social semiotic approach to contemporary communication. New York: Routledge, 2010.

LEMKE, Jay L. Letramento metamidiático: transformando significados e mídias. Trab. linguist. apl., Campinas, v. 49, n. 2, p. 455-479, Dez. 2010.

MOITA-LOPES, Luiz Paulo da (Org). Por uma linguística aplicada Indisciplinar. São Paulo: Parábola Editorial, 2006.

NEW LONDON GROUP. [1996]. A pedagogy of multiliteracies: Designing Social Futures. In: COPE, Bill; KALANTZIS, Mary (Orgs.) Multiliteracies: Literacy Learning and the Design of Social Futures. Londres/Nova York: Routledge, 2006.

ROJO, Roxane Helena Rodrigues. Letramentos Múltiplos, escola e inclusão social. São Paulo: Parábola Editorial, 2009.

Pedagogia dos multiletramentos. In: ROJO, Roxane Helena Rodrigues; MOURA, Eduardo (Orgs.).

Multiletramentos na escola. São Paulo: Parábola Editorial, 2012.

; BARBOSA, Jacqueline Peixoto. Hipermodernidade, multiletramentos e gêneros discursivos. São

Paulo: Parábola, 2015. 
SANTAELLA, Lúcia. Culturas e artes do pós-humano: da cultura das mídias à cibercultura. São Paulo: Paulus, 2003.

VOLÓCHINOV, Valentin. (1929). Marxismo e Filosofia da Linguagem: Problemas fundamentais do método sociológico na ciência da linguagem. Tradução do russo por Sheila Grillo e Ekaterina Vólkova Américo. São Paulo: Editora 34, 2017.

Recebido em 14-12-2018.

Aceito em 27-02-2019. 